\title{
Teaching non-technical skills in a data analytics program in higher education
}

\author{
Donna Cellante, Robert Morris University, cellante@rmu.edu \\ Jamie Pinchot, Robert Morris University, pinchot@rmu.e
}

\begin{abstract}
Recent literature shows that non-technical skills are as critical to success in the data analytics field as technical skills, but academia does not always include or highlight the teaching of non-technical skills in data analytics courses. This study explored the perceptions of faculty members who teach data analytics in regard to the non-technical skills they find critical, techniques they use for teaching non-technical skills, and their perceptions on the importance of non-technical skills for the entry into the data analytics profession. Ten faculty members in data analytics programs from seven colleges/universities in Pennsylvania were interviewed. Findings indicate that participants found non-technical skills to be of high importance for the data analytics field. Critical non-technical skills were identified as interpreting data effectively, communicating verbally, translating to different audiences, communicating to a non-technical audience, understanding what data to include in a data visualization, and working as part of a team. Recommendations for techniques to use to teach non-technical skills are provided.
\end{abstract}

Keywords: Non-technical skills, soft skills, communication skills, data analytics, data science, data storytelling

\section{Introduction}

Data analytics is the process of gathering large amounts of data from various sources and manipulating it to extract valuable insights and make more informed decisions (Kelley, 2020). The goal is to come up with actionable conclusions to improve business and organizational outcomes (Kelley, 2020). A data analyst is someone who uses technical skills to analyze data and report insights (Dataquest, 2020). Data analysts are responsible for collecting and organizing data, and then using that information to help solve problems or answer questions (Brooks, 2018). Data analysts play a vital role by turning data into information, providing analysis and recommendations that can be used for decision making. An analyst will often create data visualizations to display their findings and make presentations to decision makers (Hale, 2020). Organizations need someone to effectively and accurately interpret data. In order to accomplish this task, data analysts need to know how to use tools to process data, understand business scenarios, and analyze and solve basic problems (Chou, 2019).

The National Institute of Standards and Technology (NIST) defines data analytics as "the synthesis of knowledge from information" (NIST, 2015, p. 8.). Data science is a field that is closely related to data analytics, and NIST differentiates data science from data analytics, defining data science as "the extraction of actionable knowledge directly from data through a process of discovery, or hypothesis formulation and hypothesis testing" (NIST, 2015, p. 8). Despite this differentiation, these two fields are often linked and 


\section{Issues in Information Systems}

Volume 22, Issue 3, pp. 197-211, 2021

considered together in the literature. Skills and competencies needed for jobs in both fields are similar in many ways. In 2021, data scientist was ranked as the eighth best job in America by U.S. News \& World Report (100 Best, 2021), and has consistently ranked in the top ten since 2017 (Fottrell, 2017). Given the prevalence and importance of jobs in these data-related fields, it is critical to understand the skills that are necessary for these positions, and what higher education institutions can do to prepare students for careers in the data analytics industry (Clayton \& Clopton, 2019).

Previous research has shown that while there is a clear need for data analysts and data scientists to possess technical skills (Persaud, 2021; Radovilsky et al., 2018; Cegielski \& Jones-Farmer, 2016), there is also a great deal of evidence that non-technical skills are just as critical to success (Succi \& Canovi, 2020; Verma et al., 2019; Borner et al., 2018; Radovilsky et al., 2018; Cegielski \& Jones-Farmer, 2016). While technical skills are often the focus of curricula in higher education for data analytics programs, the non-technical skills are often neglected by academia (Mcbride \& Philippou, 2021; Asamoah et al., 2017).

\section{Literature Review}

When it comes to teaching data analytics, there are both technical and non-technical skills that must taught. The technical part of the field is broad and rapidly changing. Some of the technical skills required for data analysts include SQL, Tableau, data warehousing, Python, SAS, ETL, data mining, statistics/math, data modeling, Excel, programming, visualization, and machine learning (Hale, 2020; Kelley, 2020; Brooks, 2018). In addition, there is a need to bring in real-world big business data into the classroom to aid in experiential learning (Yap \& Drye, 2018).

A career in data analytics requires more than just technical know-how (Kelley, 2020). Non-technical skills, often referred to as "soft" skills, are becoming increasingly recognized and important within the workplace. LinkedIn Learning identified the top skills that companies need the most in 2020 and topping the list at numbers one through four were creativity, collaboration, persuasion, and emotional intelligence. All four of the top skills listed are considered to be non-technical (Pate, 2020). The World Economic Forum cited in their 2018 Future of Jobs report that some of the top skills trending for 2022 include active learning, creativity, critical thinking and analysis, complex problem-solving, leadership, emotional intelligence, and reasoning (World Economic Forum, 2018). Deloitte also indicates that "soft skill-intensive occupations will account for two-thirds of all jobs by 2030” (O’Mahony et al., 2017, p. 2).

The non-technical skills that often relate to the data analytics field include translating effectively, asking good questions, determining where information has been conveyed incorrectly, communicating results, explaining and documenting, presentation skills, problem-solving, research, attention to detail, teamwork, critical thinking, and creativity (Hale, 2020; Kelley, 2020; Brooks, 2018). Soft skills tend to be harder to learn because they require conscious practice (Steer, 2018). Soft skills are partly based on personality traits and partly learned through experience (Kelley, 2020).

The literature includes a variety of recent studies that have looked at critical skills required for data analysts, highlighting both technical and non-technical skills. Radovilsky et al. (2018) identified a synthesized knowledge and skill domains for both the Business Data Analytics (BDA) and Data Science (DS) professions. They found eight distinct clusters of skills needed for BDA including: business problem solving and communication, Big Data technology and languages, Office programs, general management, effective data management, database design and management, presentation and communication, and data analytics. Of these skill clusters, four were considered business-related, two were considered analytical, two were considered technical, and two were considered communication-related. Skills that were part of the definitions of the two communication-related clusters included communication skills, problem solving, 


\section{Issues in Information Systems}

Volume 22, Issue 3, pp. 197-211, 2021

creativity, collaboration, parsing complexity, developing business reports, and developing business presentations. They found six distinct clusters of skills needed for DS including: technologies and programming languages, analytical methods, communication and presentation, algorithms, business and communication, and Big Data techologies. Of these skill clusters, one was considered business-related, one was considered analytical, three were considered technical, and two were considered communicationrelated. Skills that were part of the definitions of the two communication-related clusters included written communication, non-technical communication, project communication, research, and analytical, resultsdriven, and environment-driven communication. From this study, it is clear that communication skills as well as other non-technical skills are valued and necessary for both BDA and DS positions.

Persaud (2021) used text mining on online job postings and Big Data programs at universities, as well as executive interviews to determine the required competencies that employers are seeking in data analytics professions. The study's findings indicated that employers are seeking strong functional and cognitive competencies along with a range of social skills and personality traits. Persaud (2021) defines functional competence as the ability to perform the range of activities in the job. Cognitive competencies are defined as knowledge, skills, and abilities needed to complete tasks and develop problem solving strategies. Both of these areas of competency encompass technical skills as well as non-technical skills.

Verma et al. (2019) also conducted a content analysis of online job postings related to professions in the data analytics and data science fields, such as business analyst, business intelligence analyst, data analyst, and data scientist. The study found that skills that were key to all job categories examined were decision making, organization, communication, and structured data management. Three of these four key categories of skills include non-technical skills. Decision making included non-technical skills such as reporting, analysis, problem solving, and strategic thinking. Communication included the ability to create documentation in both written and presentation formats using productivity software, which could be considered non-technical as well as technical. Organization included non-technical skills such as teamwork, ethics, self-motivation, leadership, management, and interpersonal skills.

Cegielski and Jones-Farmer (2016) studied skills needed for entry-level data analytics positions in industry. Their findings indicated that the technical skills most desired by employers were Excel, SQL, SAS, and R. Other sought-after software skills included Linux, Tableau, Hadoop, and MapReduce. In addition to technical skills, business education, communication skills, and project management skills also emerged as cornerstone skills for entry-level data analytics positions. The authors recommend that classes in data analytics include non-technical elements such as problem solving, decision making, project management, and professional oral and written communication skills.

Several studies have looked at data analytics curricula and how technical and non-technical skills should be implemented. Asamoah et al. (2017) presented an experiential perspective on the pedagogical delivery of a Big Data analytics course at a major Midwestern university. The course focused primarily on technical skills including large-scale data collection, management using Hadoop software, stream mining, visual analytics, and social network analytics. However, the course model also "emphasized professional communication skills as a cornerstone tool needed to present findings to non-data analytics experts" (Asamoah et al., 2017, p. 165).

Dzuranin et al. (2018) developed a curriculum model for integrating data analytics into an accounting curriculum. They suggested the following topics and skills for inclusion: understanding data (extracting, transforming, and loading), analysis skills (descriptive, predictive, and prescriptive statistics), communication skills (creating meaningful dashboards to convey information, creating stories to convey results), and critical thinking (asking the right questions, identifying issues, and the ability to identify data 


\section{Issues in Information Systems}

Volume 22, Issue 3, pp. 197-211, 2021

needed to address the questions). While the recommended data and analysis skills are technical in nature, the communication and critical thinking skills are non-technical. Mcbride \& Philippou (2021) also analyzed masters programs in accounting to determine the most critical skills required for the effective use of Big Data and data analytics. The authors grouped the critical skills found into four thematic areas: questioning and scepticism, critical thinking skills, understanding and the ability to analyze, and communication results. They found that most accounting programs incorporate questioning and skepticism as well as the ability to analyze, but often lack elements that focus on teaching critical thinking and communication skills.

Cybulski et al. (2015) developed a framework for utilizing interactive visual analytics, such as dashboards and other data visualizations, to employ various aspects of digital creativity to explore data and use it to make effective business decisions. The authors posit that data visualization is an important skill that both data analysts and "ordinary people" can use to explore novel ways to view and gain insights from Big Data.

Borner et al. (2018) studied the alignment between skills and expertise needed in the data analytics workforce to skills provided by academia. Their findings highlighted the "increasing importance of human skills such as communication, negotiation, and persuasion" (p. 12630) along with an increased demand within the workforce for non-technical "soft" skills such as teamwork and communication, as well as the traditional "hard" technical skills and tools.

Results of a study by Succi \& Canovi (2020) that examined and compared students' and employers' perceptions regarding the importance of soft skills in different European countries show that $86 \%$ of respondents indicate an increased emphasis on soft skills over the last 5-10 years and that companies consider soft skills more important than students/graduates.

\section{Purpose of the Study}

Recent literature clearly shows that non-technical skills are just as critical to success in the data analytics field as technical skills (Succi \& Canovi, 2020; Verma et al., 2019; Borner et al., 2018; Radovilsky et al., 2018; Cegielski \& Jones-Farmer, 2016), but academia does not always highlight non-technical skills when teaching data analytics courses (Mcbride \& Philippou, 2021; Asamoah et al., 2017).

The purpose of this exploratory study was to provide a framework to further emphasize non-technical skills in data analytics programs in higher education by highlighting the most important non-technical skills for data analytics and best practices for teaching these skills. The following research questions were explored:

RQ1: What are the perceptions of professors teaching data analytics about the importance of nontechnical skills for entry-level data analytics positions?

RQ2: What do professors teaching data analytics believe are most important non-technical skills for data analytics?

RQ3: What do professors teaching data analytics believe are the best approaches for teaching nontechnical skills? 


\section{Issues in Information Systems}

Volume 22, Issue 3, pp. 197-211, 2021

\section{Methodology}

For this exploratory study, we interviewed 10 faculty members in data analytics programs from seven colleges/universities in Pennsylvania. The faculty members were asked about their perceptions of the importance of non-technical skills for entry-level data analytics positions and about the approaches that they use to teach non-technical skills in their data analytics courses.

Before contacting any potential participants, we received approval for this study from the university's Institutional Review Board (IRB). Following IRB approval, we identified colleges/universities in western Pennsylvania with data analytics or data science programs as a first step to recruiting participants. Faculty teaching in the program were identified and their email addresses were recorded into an Excel spreadsheet. The various faculty were sent an email asking them to participate in the study. If they responded yes, a mutual date/time was selected for the interview via Google Meet, an online video-conferencing tool.

An interview is a guided conversation for gathering information when researchers ask one or more participants general, open-ended questions and record their answers (Creswell \& Creswell, 2018). We conducted one-on-one semi-structured interviews. This allowed the researchers to follow a predetermined set of questions, but to also probe the participants based on the respondent's answers or ask supplementary questions for clarification (Jarvinen \& Mik-Meyer, 2020). Interview questions were derived from the literature review, and some of the interview questions were adapted from Gruzdev et al. (2018). The full list of interview questions is provided in the appendix.

Participants were provided informed consent forms and signed before interviews were conducted. These forms assured participants that their names and universities would be kept confidential. All interviews were audio recorded while each of the researchers took notes as well. Audio recordings from each interview were transcribed using Otter.ai and reviewed by hand for accuracy. We conducted a thematic analysis of the interview transcripts. The first round of coding was done individually by each researcher. Then, we compared codes and came to a consensus. We jointly determined the themes that emerged from the coding and analysis process.

\section{Results}

The participants included 10 faculty members colleges and universities in Pennsylvania. Each of the participants taught data analytics, data science, data mining, data integration, or statistics/math. The participants years of teaching ranged from 3 years to 36 years, with an average of 14.5 years.

RQ1 asked What are the perceptions of professors teaching data analytics about the importance of nontechnical skills for entry-level data analytics positions? In order to address this research question, participants were directly asked how important they believe it is for students to master non-technical skills in order to obtain an entry-level position in data analytics. Eighty percent (8/10) of the participants believe that the nontechnical/soft skills are extremely important for students to learn. This need was described as absolutely necessary, extremely important, and nearly critical. One participant stated:

"I think it is extremely important, all of the research that we've done in the past shows it's very important for the employers who hire our students. We hear this reiterated by employers all the time how important communication skills and soft skills are."

However, though the majority of participants responded favorably, thirty percent (3/10) also directly stated that while they think non-technical skills are important, they do not teach them in their courses. One 


\section{Issues in Information Systems}

Volume 22, Issue 3, pp. 197-211, 2021

participant noted that professional communication skills are taught at his university, but they are taught as stand-alone courses and are not incorporated into the data analytics curriculum. Another participant noted that he does not include non-technical skills in his data analytics courses because there is simply not enough time to include them. Finally, a participant noted that he did not teach non-technical skills because he was never trained to teach those types of skills, and focuses in his classes only on technical content. When first asked about non-technical skills, this participant stated:

“They're important. I don't know how to teach them."

In order to answer RQ2, 14 questions were asked to explore the participants' views about non-technical skills. The skills that were explicitly asked about included problem-solving, teamwork, critical thinking/analysis, interpretation of data, written and oral communication, and attention to detail/accuracy.

RQ2 asked What do professors teaching data analytics believe are most important non-technical skills for data analytics? Our data analysis produced six themes that encompass the non-technical skills that the participants found to be most important for data analytics courses. Each theme is listed along with a count showing the number of times the concept was coded in the interview transcripts and a definition of the theme in Table 1.

Table 1. Themes representing most important non-technical skills for data analytics from participants

\begin{tabular}{|l|l|l|}
\hline Theme & $\begin{array}{l}\text { Coun } \\
\text { t }\end{array}$ \\
\hline Interpreting data effectively & 22 & Ability to interpret data to answer business questions \\
\hline Communicating verbally & 21 & $\begin{array}{l}\text { Ability to communicate effectively via verbal } \\
\text { presentations }\end{array}$ \\
\hline Translating to different audiences & 12 & $\begin{array}{l}\text { Ability to tailor explanations and interpretations of data } \\
\text { for a specific audience }\end{array}$ \\
\hline $\begin{array}{l}\text { Communicating to a non-technical } \\
\text { audience }\end{array}$ & 8 & $\begin{array}{l}\text { Ability to communicate explanations and interpretations } \\
\text { of data to an audience that may not understand technical } \\
\text { jargon, methods, or software }\end{array}$ \\
\hline $\begin{array}{l}\text { Understanding what data to } \\
\text { include in a data visualization }\end{array}$ & 7 & $\begin{array}{l}\text { Ability to determine what data should and should not be } \\
\text { included in a data visualization in order to ensure clarity } \\
\text { of information }\end{array}$ \\
\hline Working as part of a team & 6 & \begin{tabular}{l} 
Ability to work effectively as a member of team \\
\hline
\end{tabular} \\
\hline
\end{tabular}

\section{Interpreting Data Effectively}

Interpreting data effectively was the theme that had the most mentions by participants in the study. It was clearly seen as important for data analysts to be able to not only effectively analyze data, but also to interpret the data analysis effectively. If a student is not able to verbalize, express in writing, or visualize an adequate interpretation of data to answer business questions, then the analysis has not been effective. Several excerpts from participants illustrate this theme: 


\section{Issues in Information Systems}

Volume 22, Issue 3, pp. 197-211, 2021

"If you are not able to explain what you have found in the data, your wonderful, beautiful, very technical model, beautiful code will be absolutely nothing to the person who is going to go to your decision makers."

"A data analyst should be someone who can communicate how and what they found in the data, and that communication should be a combination of being able to explain it, write reports, and then also to be able to visualize data."

"I use the oral presentation to get them to really discuss the findings and implications of the findings, and how those findings can be applied to the business scenario for better decision making."

"We do a lot with what we call data storytelling... I kind of have them take their key points write them down, and then try to add descriptors or explanations in independently on each point. And then I, I try to show them, well, we have four pieces of analysis, and we have all these different, what I call descriptors. Where do we have overlap? Well, that overlap now gives us really cool discussion points when we start pulling these pieces together."

The final excerpt introduces an interesting concept of data storytelling. The participant uses this phrase to describe the process of interpreting individual pieces of a data analysis to find the patterns and develop a story (interpretation) that ties together all of the pieces. Data storytelling is defined in the literature as an information compression technique for communicating data insights to an audience using a combination of narrative and data visualization techniques (Martinez-Maldonado et al., 2020). It has roots in visual design and often results in several data stories that are crafted by a data analyst. The analyst identifies key insights from the data and creates a visualization that highlights a specific insight per data story. For example, a chart might have the key item of interest highlighted by changes in size, color, or by adding text or callout markers to highlight only the data points pertinent to the data story (Knaflic, 2015). This excerpt clearly illustrates how this professor teaches the narrative form of data storytelling.

\section{Communicating Verbally}

Communicating verbally was a theme that emerged with the second highest number of mentions from participants. The ability to effectively present information orally to different audiences is a key skill for data analysts. The following excerpts from participants illustrate this theme:

"I think that presentation skills are so important that I incorporate spoken activities with every project that I do, even the software projects."

"Verbal communication I think is one of the most important things, you know you're going to have to get up in front of people and you're going to have to be able to talk about your analysis and your findings. A lot of the time you might communicate findings in dashboards or visualizations, but being able to get up in front of people and explain is crucial."

"We do a decent amount of actual presentation in our courses. I know students don't love it, but I hate to say in this field, they have to get used to it."

\section{Translating to Different Audiences}

The third theme, translating to different audiences, was something that participants spoke passionately about in the interviews. Participants stressed that an analyst must be able to tailor a presentation or interpretation to a specific audience, because different stakeholders will want to consume the information 


\section{Issues in Information Systems}

Volume 22, Issue 3, pp. 197-211, 2021

in different ways. Key insights from data analysis will be more impactful when tailored correctly to the audience. Some key excerpts highlighting this theme include:

"One of the things that we teach in analytics is that the level of detail has to be specific to your audience. So, back to the scenarios that I give them to the project. So, you know, if I say, the audience for this dashboard is operation. For operation level managers, I would expect them to use, you know very, very low levels of detail and daily, you know, transactional figures, as opposed to if the scenario you're putting together is something for senior management, you know for a CEO or CFO or what have you, then I would expect them to provide very summarized, aggregated levels of detail. They need to present their findings and recommendations in the appropriate level of detail for that audience."

"CFOs just want to get a five second interpretation of what they're seeing on the screen. And so you need to show them the five second, wow, business insight. They're not interested in the detail and you need to be able to stand back and present the data to the targeted audience, what they are looking for what is on their plate that they have to manage in the business."

"We try to do the different tiers of presentations, so we may do the C-level presentation, but then we also do what I call the drive by, where like I'll walk in one day and just ask them a question and they have to be able to prepare and respond to that question about the data because you just never know when that's going to pop up."

\section{Communicating to a Non-Technical Audience}

Another interesting theme that emerged from the study was communicating to a non-technical audience. This theme parallels the theme of translating to different audiences, but focuses specifically on the idea that data analysts need to be able to effectively communicate results to business stakeholders in a way that lets the stakeholders clearly understand the implications of data insights for their business needs even if they do not necessarily understand the technical details of how the key insights were derived. This theme focuses on communicating clearly in plain language without technical jargon. A key excerpt to illustrate this theme is:

"One of the stipulations for the project is that they consider their audience as, I don't like the phrase but I think it's what we use, as educated non-experts. The point is that they are not experts. And so I encourage them to talk to each other as decision makers in simulated organizations where there are people that don't know what a confidence interval is, and they don't want to feel dumb, not knowing what a confidence interval is. So your job is to talk to them as people that care about data and the data analytic process but may not understand the reasoning and the drivers behind the decisions that one might recommend."

\section{Understanding What Data to Include in a Data Visualization}

The theme of understanding what data to include, and what data not to include, in a data visualization is in many ways related to the ability to identify key insights from data and interpret those insights clearly. When you are able to interpret data effectively, then this theme is an extremely helpful complementary skill. This theme focuses on the importance of understanding how to isolate items that relate to the insight that you wish to highlight. It also parallels quite nicely with the concept of data storytelling and crafting a data story to illustrate a key insight. Items that do not aid the story should be left out. In particular, chart junk, a term coined by Edward Tufte (1983) in his book The Visual Display of Quantitative Information, should also be avoided. Chart junk is unnecessary content added to charts or visualizations just to fill in empty space. Some key excerpts for this theme include: 


\section{Issues in Information Systems}

Volume 22, Issue 3, pp. 197-211, 2021

"What types of graphs and charts are most appropriate depend on what type of data that you're working with. And then, in recent years I've been trying to also include in like, what the goal of your message is as well. So, I am also trying to work more into these lessons about what your goal to convey is as well and so not just focus on what type of data but what's my message that I'm trying to get across."

"I use the term Play-Doh the data, like when you get that first container of Play-Doh, you just kind of sit there and massage it and play with it and just, whatever. You just never know just from the visuals where they may lead you as you look at different views of the data."

"Chart junk is people putting these random data points or clipart pictures in the middle of their bar chart, because they felt like they didn't want to have a white spot there so I asked the students, how can you quantify how bad that is?"

\section{Working as Part of a Team}

The final theme of working as part of a team highlights the fact that in the data analytics field, you will seldom be able to work alone. Analysts are typically part of a larger project team that could include members from various different parts of a business. It is critical that students understand that teamwork is an essential skill for success in the data analytics field. Some excerpts that illustrate this theme include:

"I think the roles that our students are looking at are almost always roles in which they're working on an interdisciplinary team and they're not buried in a lab, where their only clients are other technical folk."

"All my classes, whether it be analytics data mining, or similar classes, everything is grouped for teamwork. And I'm not just having them working as a team, like where you're going to come together and just start working. We talk about like, team formation, we talk about how, you know, if there are team conflicts, how we can solve those team conflicts, and I show them that similar to how you might be working in the real world, where you might be the analyst, but you're working with a machine learning engineer and you're working with the data engineer so you have to know how to fit into that, the team dynamics of it."

"We enforce teamwork in almost all the courses, because we'll say that in industry you cannot work by yourself. It is teamwork. So you know, in some classes, what we do is we combine students from mechanical engineering and business analytics, as team members, maybe six to 10 people so the thing is, they get the real exposure of team dynamics."

RQ3 asked What do professors teaching data analytics believe are the best approaches for teaching nontechnical skills? In order to answer RQ3, the same 14 questions used to explore the participants' views about non-technical skills for RQ2 were analyzed. Rather than conducting thematic analysis for RQ3, our data analysis looked for insightful comments and ideas related to teaching non-technical skills that were discussed in the interviews. Thematic analysis was not used because some of the most insightful ideas that emerged from the data set for teaching practices were often only described by one of the participants. So, instead, the data was analyzed to compile lists of the most useful responses about teaching for each of the non-technical skillsets discussed.

\section{Teaching Problem Solving}

The participants give their students business scenarios which address questions and objectives. They also give applied examples (data sets that are open ended), not step-by-step directions. The students must 


\section{Issues in Information Systems}

Volume 22, Issue 3, pp. 197-211, 2021

formulate the problem, discuss it, and then explain the results. By using open-ended data sets, the students must figure out which method or technique would be best.

\section{Teaching Critical Thinking/Analysis}

The participants explained that there are certain patterns that have become the standard. They provide frameworks with steps and examples. The participants mentioned the software tools they use, but stressed that the tools are secondary. The student must have an understanding of concepts to use the tools. Participants mentioned the analytics life cycle and the data science life cycle, requiring students to divide the problem into different parts and set goals. Requiring students to write short summaries explaining their findings allows students to interpret data and write the results in non-technical terms.

\section{Teaching Teamwork}

Almost all of the participants use group (team) projects to teach this concept. Almost half of the classes used projects. "You don't teach teamwork per se!" The students have to figure out how to fit into team dynamics. In industry, no one works alone. Peer reviewing was mentioned as a way to practice and evaluate performance of the team. Seven of the ten participants do not assign the groups. They allow the students to self-discover the roles. Students assume leadership roles themselves. For the others that do assign groups, they match students based on individual strengths and weaknesses. Allowing students to evaluate the performance of the team members becomes part of the grade. The students give feedback on the members weekly.

\section{Teaching Accuracy and Thoroughness}

The participants mentioned the importance of accuracy, thoroughness of information, and checking error rate. The students have to interpret what's missing or misinterpreted. They make mini presentations throughout each phase. They make a formal presentation at the end where they are asked questions for clarification. Interpretation is very important at this level.

\section{Teaching How to Communicate Results}

Most of the participants require students to compose project findings, depending on the audience. Presenting the results orally was important, too. One participant mentioned that you want students to "look at results - not over them." Stressed sensibility analysis - does this make sense? What other factors need to be taken into account? Interpretation is very important. Almost all of the participants noted that the students must explain the information in multiple ways. One participant mentioned that they must "do so publicly" meaning that others see and scrutinize the data. Another participant said they must use the "data story telling" method. The students must explain the problem, method, and conclusions. Small projects allow students to use the insights - let them see the gaps in knowledge.

\section{Teaching How to Communicate Effectively in Writing and Verbally}

The participants require students to use presentations to communicate their findings. The students must orally communicate their findings, whether it's to a large group or small group. The presentation must explain what they did in their own words. The students must provide written documentation for every project (2-3 pages). They must explain what they did to answer the question or solve the problem, using proper grammar and spelling. It must be professional and aimed at the appropriate audience. 


\section{Issues in Information Systems}

Volume 22, Issue 3, pp. 197-211, 2021

\section{Teaching How to Analyze Data Objectively}

The participants mentioned that this is difficult to do. Students assume black and white answers. One participant uses social media data to analyze. There is less issue with structured data. You need to provide examples and factor models. One participant said, "I am a complete jerk-every semester I make the students submit their data for approval. I teach them how to interpret from an alternate perspective." Another participant said, "There's no one size fits everything! Data is speaking for itself."

\section{Discussion}

Six major themes were identified as a framework of the most critical non-technical skills to teach in data analytics courses. The themes are interpreting data effectively, communicating verbally, translating to different audiences, communicating to a non-technical audience, understanding what data to include in a data visualization, and working as part of a team. So what does this mean to faculty teaching in these programs? It is most important that students are able to interpret data well. Students have to understand the data, explain the data, and interpret the data. They must be able to explain the information in multiple different ways, tailoring the level of detail to the audience. The students must be able to communicate to various audiences in a non-technical way.

Since oral presentations were stressed more than written results, students need practice in getting up in front of the class and presenting their findings. Students must be able to get the goal across, by explaining in their own words. It was mentioned that time is a factor in teaching courses, but faculty would be remiss if they ignored opportunities to get students comfortable presenting their results.

Understanding what data to include in a data visualization takes practice as well. Faculty need to teach how to build a dashboard, how to filter, and how to arrange. Students need to be taught about data points and analysis, then data visualization. Faculty need to show students how to put together the analysis, then the visuals. Faculty need to stress to students, what is the goal of your message? Faculty need to show students how to plot and then interpret in different ways.

Teamwork is very important, too. Almost all participants use group/team projects for the majority of their courses. Faculty need to use group projects to teach students about group dynamics, team formation, and team conflicts. Students need to be accountable for their part in the process. Each member of the group evaluates the performance of other members of the group.

\section{Conclusions/Recommendations}

The literature shows that non-technical skills are as critical in the data analytics field as technical skills, but academia needs to include or highlight these skills more. The six themes identified point to the most critical non-technical skills for data analytics: interpreting data effectively, communicating verbally, translating to different audiences, communicating to a non-technical audience, understanding what data to include in a data visualization, and working as part of a team. What can faculty members do to effectively begin to teach these non-technical skills in data analytics to help prepare their students for careers in the field? Table 2 indicates the best approaches to teaching problem solving, critical thinking/analysis, teamwork, accuracy and thoroughness, how to communicate results, how to communicate effectively in writing and verbally, and how to analyze data objectively. The recommendations are suggestions for faculty to use in the classroom. 


\section{Issues in Information Systems}

Volume 22, Issue 3, pp. 197-211, 2021

Table 2: Recommendations for best approaches to teaching

\begin{tabular}{|l|l|}
\hline Problem Solving & $\begin{array}{l}\text { Use scenarios, projects, examples, and open- } \\
\text { ended questions }\end{array}$ \\
\hline Critical Thinking/Analysis & $\begin{array}{l}\text { Teach by example; use scenarios, frameworks, } \\
\text { case studies, and summaries }\end{array}$ \\
\hline Teamwork & $\begin{array}{l}\text { Use group/team projects which include formal } \\
\text { presentations at the end }\end{array}$ \\
\hline Accuracy and Thoroughness & $\begin{array}{l}\text { Use large data sets, examples, and missing data } \\
\text { exercises }\end{array}$ \\
\hline How to Communicate Results & $\begin{array}{l}\text { Use projects, explanation, examples, data } \\
\text { storytelling, and summaries }\end{array}$ \\
\hline How to Communicate Effectively in Writing and & $\begin{array}{l}\text { Require written documentation explaining what } \\
\text { was done to various audiences and then present } \\
\text { orally }\end{array}$ \\
\hline How to Analyze Data Objectively & $\begin{array}{l}\text { Use examples, factor analysis, ethics, and } \\
\text { discussion }\end{array}$ \\
\hline
\end{tabular}

The researchers know the importance of time in presenting all of the concepts necessary for students to perform well in the field. They also recognize the importance of teaching using best approaches. The above recommendations are suggestions of techniques that could be incorporated into the classroom without dramatic changes. Scenarios, examples, and projects are a natural way to learn the data analytics field before actually entering the field. These teaching techniques can be implemented in ways that support the incorporation of the six non-technical skills themes into data analytics courses.

Future research could be conducted using a larger sample size. Also, the study could incorporate more states than just Pennsylvania.

\section{References}

100 best jobs. (2021). U.S. News \& World Report. https://money.usnews.com/careers/bestjobs/rankings/the-100-best-jobs

Asamoah, D., Sharda, R., Zadeh, A., \& Kalgotra, P. (2017). Preparing a data scientist: A pedagogic experience in designing a Big Data analytics course. Decision Sciences Journal of Innovation Education, 15(2), 161-190.

Borner, K., Scrivner, O., Gallant, M., Ma, S., Liu, X., Chewning, K., Wu, L, \& Evans, J.A. (2018). Skill discrepancies between research, education, and jobs reveal the critical need to supply soft skills for the data economy. Proceedings of the National Academy of Sciences, 115(50), 12630-12637.

Brooks, A. (2018, Nov. 19). 15 data analyst skills that will catch the eye of employers. https://www.rasmussen.edu/degrees/technology/blog/data-analyst-skills/

Cegielski, C.G., \& Jones-Farmer, L.A. (2016). Knowledge, skills, and abilities for entry-level business analytics positions: A multi-method study. Decision Sciences Journal of Innovative Education, 14(1), 91-118. 


\section{Issues in Information Systems}

Volume 22, Issue 3, pp. 197-211, 2021

Chou, L. (2019, Oct. 16). 6 key skills that data analysts need to master. Towards Data Science. Https://towardsdatascience.com/6-key-skills-that-data-analysts-need-to-master-df1d82257b9

Clayton, P.R., \& Clopton, J. (2019). Business curriculum redesign: Integrating data analytics. Journal of Education for Business, 94(1), 57-63.

Creswell, J. \& Creswell, J. (2018). Research design: Qualitative, quantitative, and mixed methods approaches $\left(5^{\text {th }} E d\right.$.). Sage.

Cybulski, J.L., Keller, S., Nguyen, L., \& Saundage, D. (2015). Creative problem solving in digital space using visual analytics. Computers in Human Behavior, 42, 20-35.

Dataquest. (2020, August 12). Data analyst skills-8 skills you need to get a job. Dataquest. https://www.dataquest.io/blog/data-analyst-skills/

Dzuranin, A.C., Jones, J.R., \& Olvera, R.M. (2018). Infusing data analytics into the accounting curriculum: A framework and insights from faculty. Journal of Accounting Education, 43, 24-39.

Fottrell, Q. (2017). The most sought-after job in America pays $\$ 110,000$ a year - if you have this skill. MarketWatch: Stock Market News. http://www.marketwatch.com

Gruzdev, M., Kuznestsova, I., Tarkhanova, I \& Kazakova, E. (2018). University graduates' soft skills: The employer's opinion. European Journal of Contemporary Education, 7(4). ISSN: 23056746.

Hale, J. (2020, Jan. 14). Most in-demand tech skills for data analysts. Towards Data Science. https://towardsdatascience.com/most-in-demand-tech-skills-for-data-analysts-26d4ea4450f8

Jarvinen, M. \& Mik-Meyer, N. (2020). Qualitative analysis: Eight approaches for the social sciences. Sage.

Kelley, K. (2020, Sept. 26). Data analyst skills that you need to master. Simplilearn.com. https://www.simplilearn.com/data-analyst-skills-article

Knaflic, C.N. (2015). Storytelling with data: A data visualization guide for business professionals. John Wiley \& Sons.

Martinez-Maldonado, R., Echeverria, V., Fernandez Nieto, G., \& Buckingham Shum, S. (2020). From data to insights: A layered storytelling approach for multimodal learning analytics. Proceedings of the 2020 CHI Conference on Human Factors in Computing Systems, 1-15.

Mcbride, K., \& Philippou, C. (2021). "Big results require big ambitions": Big data, data analytics and accounting in masters courses. Accounting Research Journal. https://doi.org/10.1108/ARJ-042020-0077

NIST Big Data Public Working Group Definitions and Taxonomies Subgroup. (2015). NIST Big Data Interoperability Framework: Volume 1, Definitions (Final Version 1).

http://dx.doi.org/10.6028/NIST.SP.1500-1 


\section{Issues in Information Systems}

Volume 22, Issue 3, pp. 197-211, 2021

O’Mahony, J., Rumbens, D., Mizrahi, J., Hull, N., \& Xmith, X. (2017). Soft skills for business success. Deloitte Access Economics. https://www2.deloitte.com/au/en/pages/economics/articles/softskills-business-success.html

Pate, D.L. (2020, January 13). The skills companies need most in 2020 - And how to learn them. http://ir.westcliff.edu/wp-content/uploads/2020/01/The-Skills-Companies-Need-Most-in2020\%E2\%80\%94And-How-to-Learn-Them.pdf

Persaud, A. (2021). Key competencies for big data analytics professions: A multimethod study. Information Technology \& People, 34(1), 178-203. https://doi.org/10.1108/ITP-06-2019-0290

Radovilsky, Z., Hegde, V., Acharya, A., \& Uma, U. (2018). Skills requirements of business data analytics and data science jobs: A comparative analysis. Journal of Supply Chain and Operations Management, 16(1), 82-101.

Steer, D. (2018, Dec. 4). How to develop the five soft skills that will make you a great analyst. Mode Blog. https://mode.com/blog/how-to-develop-the-five-soft-skills-that-will-make-you-a-greatanalyst/

Succi, C. \& Canovi, M. (2020). Soft skills to enhance graduate employability: Comparing students and employers' perceptions. Studies in Higher Education, 45(9), 1834-1847. doi: 10.1080/03075079.2019.1585420

Tufte, E. (1983). The visual display of quantitative information. Graphics Press.

Verma, A., Yurov, K.M., Lane, P.L., \& Yurova, Y.V. (2019). An investigation of skill requirements for business and data analytics positions: A content analysis of job advertisments. Journal of Education for Business, 94(4), 243-250.

World Economic Forum. (2018, September 17). The future of jobs report 2018. Center for the New Economy and Society.

Yap, A. \& Drye, S. (2018). The challenges of teaching business analytics: Finding real big data for business students. Information Systems Education Journal, 16(1). ISSN: 1545-679X. 


\section{Issues in Information Systems}

Volume 22, Issue 3, pp. 197-211, 2021

\section{Appendix: Interview Questions}

How important do you believe it is for students to have mastered the nontechnical/soft skills in order to obtain an entry-level position in data analytics?

Problem-solving

1. How do you teach your students to use their problem-solving capabilities?

2. *How do you teach your students to search, to do critical analysis of information, and apply a systematic approach to solving problems?

3. *How do you teach your students to determine the range of tasks to achieve the goal and to choose the best ways to solve them?

Teamwork

4. How do you teach your students about the importance of teamwork?

5. *How do you teach your students to carry out social interaction and realize their own role in the team?

Critical Thinking/Analysis/Interpretation

6. How do you teach your students to determine whether information has been conveyed correctly or completely?

7. How do you teach your students to translate what they find into written form?

8. How do you teach your students to interpret, explain, and document what they find?

Communications

9. How do you teach your students to communicate their results?

10. How do you teach your students to ask good questions?

11. How do you teach your students to communicate orally and in writing in different settings effectively?

Attention to Detail/Accuracy

12. How do you teach your students about attention to details?

13. How do you teach your students to analyze data objectively to come up with accurate evaluations?

*Note: Adapted from Gruzdev et al. (2018) 